\title{
APLIKASI CROPWAT 8.0 SEBAGAI UPAYA MENGANALISA KEBUTUHAN AIR IRIGASI DAN HASIL PRODUKSI TANAMAN JAGUNG DI KELURAHAN MATALAMAGI KOTA SORONG
}

\author{
Hendrik Pristianto $^{1)}$, Mulyadi Mulyadi ${ }^{2)}$ \\ ${ }^{1), 2)}$ Program Studi Teknik Sipil Universitas Muhammadiyah Sorong \\ Jalan Pendidikan No 27 Kota Sorong, Propinsi Papua Barat \\ Email : tekniksipilsorong@gmail.com
}

\begin{abstract}
ABSTRAK
Kelurahan Matalamagi merupakan lahan sawah tadah hujan dataran rendah dimana lahan sawah ini umumnya terkendala oleh ketersediaan air yang dipengaruhi oleh curah hujan dan kemampuan tanah menahan air. Tujuan penelitian ini pada lahan pertanian tadah hujan ditekankan bagaimana menganalisa kebutuhan air irigasi dan memaksimalkan hasil produksi tanaman jagung dengan menggunakan aplikasi Cropwat 8.0 sebagai alternatif kompleks jika dibandingkan menggunakan perhitungan empiris dengan metode yang beraneka ragam. Analisa perhitungan kebutuhan air irigasi tanaman jagung dengan Cropwat 8.0 dimaksudkan sebagai dasar jumlah air yang akan diaplikasikan pada kegiatan irigasi dan pemberian air irigasi di kelurahan Matalamagi. Adapun model pola tanam dan masa tanamnya disimulasikan pada kondisi cuaca wilayah kelurahan Matalamagi dengan periode pengamatan 2003 sampai dengan 2012. Hasil analisa kebutuhan air tanaman jagung yang dibagi dalam empat masa tanam memiliki nilai variatif. Kebutuhan air tanaman tiap masa tanam terjadi penurunan akibat stress kekurangan air di daerah perakaran sehingga menyebabkan pula menurunnya hasil produksi pada lahan kondisi tadah hujan. Hal ini menunjukkan bahwa tingkat deplesi lengas tanah selama periode tanam sangat besar sehingga jumlah air yang dibutuhkan untuk mengisi daerah perakaran pun semakin besar.
\end{abstract}

Kata kunci : Cropwat, Deplesi Lengas Tanah, Hasil Produksi, Kebutuhan Air Tanaman.

\section{PENDAHULUAN}

\section{Latar Belakang}

Kelurahan

Matalamagi

merupakan salah satu kelurahan yang berada pada Distrik Sorong Utara yang memiliki usaha pertanian yang berkembang khususnya pada tanaman

Perhitungan kebutuhan air irigasi tanaman untuk lahan tadah hujan diharapkan dapat membantu dalam palawija yang berupa tanaman jagung. Ketersediaan air di lahan ini umumnya dipengaruhi oleh curah hujan dan kemampuan tanah menahan air. Peluang untuk meningkatkan produksi tanaman pada pertanian tadah hujan ditekankan bagaimana memaksimalkan produksi per unit air.

pembuatan kebijakan tentang cara yang efektif dalam penggunaan sumber daya air yang terbatas sehingga tidak terjadi 
kekurangan air pada musim kemarau yang dapat memenuhi kebutuhan air irigasi dan tidak terjadi kelebihan air pada musim hujan yang mengakibatkan air terbuang percuma tanpa adanya pemanfaatan sehingga menjadi aliran permukaan.

Cropwat 8.0, yaitu program berbasis windows yang digunakan untuk menghitung kebutuhan air irigasi berdasarkan data tanah, data iklim dan data tanaman. Program ini dipergunakan untuk menghitung evapotranspirasi tanaman (ETc), evapotranspirasi acuan (ETo), kebutuhan air irigasi satu jenis tanaman maupun beberapa jenis tanaman.

\section{Batasan Masalah}

Untuk memperjelas permasalahan dan memudahkan dalam menganalisa, maka dibuat batasan masalah. Adapun batasan masalah dalam penelitian ini yaitu sebagai berikut.

1) Perhitungan kebutuhan air tanaman jagung menggunakan program Cropwat 8.0 dengan metode PenmanMonteith.

2) Tidak menghitung alternatif pola tanam karena berpengaruh terhadap kebutuhan air tanaman yang ditinjau.

3) Tidak memperhitungkan debit air tampungan.

\section{Tujuan Penelitian}

Adapun tujuan penelitian ini yaitu sebagai berikut.

1) Untuk mengetahui kondisi sifat fisik tanah yang akan ditanami tanaman jagung di Kelurahan Matalamagi.
2) Untuk mengetahui kondisi pola tanam di lahan pertanian kelurahan Matalamagi.

3) Untuk mengetahui analisa kebutuhan air irigasi tanaman jagung dari tahap penanaman hingga panen dengan program Cropwat 8.0 di Kelurahan Matalamagi.

4) Untuk mengetahui analisa hasil produksi relatif tanaman jagung dengan Cropwat 8.0

\section{METODOLOGI PENELITIAN}

\section{Lokasi Penelitian}

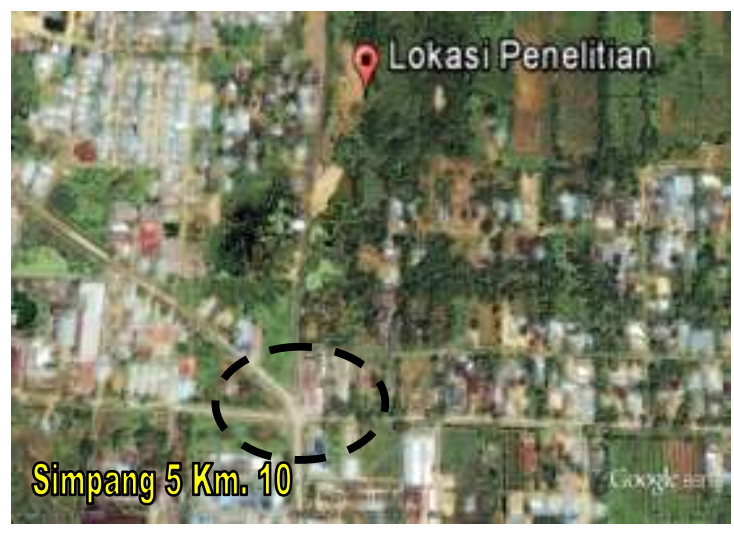

Gambar 1. Lokasi Penelitian

Penelitian ini secara umum dilaksanakan di Kota Sorong, dengan mengambil lokasi penelitian di Areal lahan Pertanian Jalan TPU Km.10 Kelurahan Matalamagi Sorong Distrik Sorong Utara.

\section{Teknik Pengumpulan Data}

Pengumpulan data terbagi dua yaitu data primer dan data sekunder. Data primer yang dilakukan yaitu dengan pengujian laboratorium di Laboratorium Dasar Universitas Muhammadiyah Sorong 
dimana variabel yang meliputi penetapankadar air tanah kapasitas lapang field capacity). Sedangkan data sekunder diperoleh dari BMKG Klas I Bandara DEO Sorong berupa data iklim selama 10 Tahun dengan periode pengamatan 2003 s.d. 2012.

\section{Teknik Pengolahan dan Analisis Data}

Teknik pengolahan data dalam penelitian ini menggunakan empat panel utama dalam program Cropwat 8.0 yaitu Climate/ETo (Data Iklim), Rain (Data Hujan), Crop (Data Tanaman) and Soil (Data Tanah). Adapun proses pengopeasiannya dengan menginput data kedalam panel yang telah tersedia. Setelah semua data diatas telah diinput, maka didapat hasil analisis kebutuhan air tanaman pada panel terakhir CWR (Crop Water Requirement) dan Schedule untuk mengetahui nilai neraca lengas tanah dan hasil produksi relatif tanaman jagung.

Semua metode penulisan dan analisa dalam artikel ilmiah ini merujuk pada panduan penulisan tugas akhir Fakultas Teknik Universitas Muhammadiyah Sorong tahun 2014 (Pristianto, Amri, \& Rusdi, 2014).

\section{HASIL PENELITIAN DAN PEMBAHASAN}

\section{Kondisi Pola Tanam dan Masa Tanam}

Berdasarkan hasil wawancara bersama ketua kelompok "Rukun Tani" di lokasi studi didapatkan bahwa pola tanam yang digunakan petani dalam setahun yaitu pola tanam monokultur yaitu jagung

semua dengan luas areal lahan pertanian \pm $5000 \mathrm{~m}^{2}$. Dimana dibagi dalam empat kali masa tanam atau biasa disebut IP400 (jagung - jagung - jagung - jagung) dengan jenis jagung berumur pendek (genjah) berkisar hingga 75 - 90 hari. Masa tanam pertama (MT 1) dimulai dari tanggal 29 November s.d. 26 Februari, MT 2 tanggal 28 s.d. 28 Mei, MT 3 pada tanggal 30 Mei s.d 27 Agustus dan masa tanam terakhir yaitu MT 4 dimulai dari tanggal 29 Agustus s.d 27 November.

\section{Analisa Evapotranspirasi Acuan (Climate/ETo)}

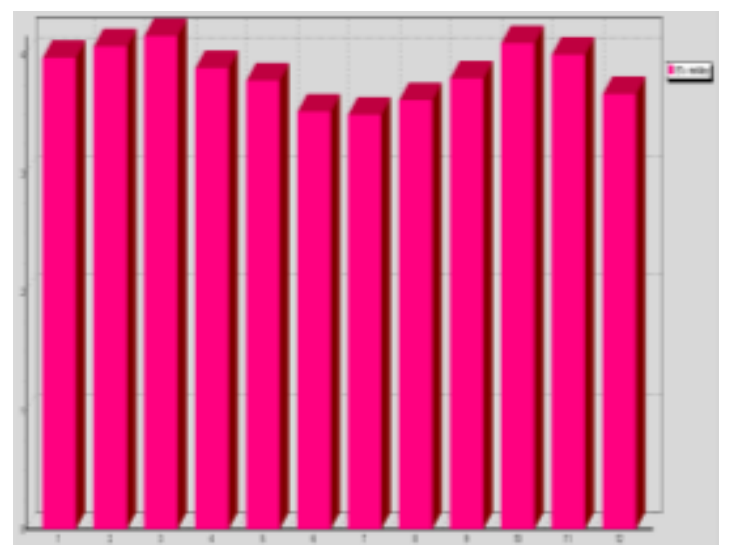

Gambar 2. Grafik Hasil Input Data Iklim pada Cropwat 8.0

Berdasarkan hasil analisa cropwat 8.0 didapat bahwa nilai evapotranspirasi rata - rata adalah sebesar 3,84 $\mathrm{mm} /$ hari dengan total jumlah nilai evapotranspirasinya sebesar 46,14 $\mathrm{mm} /$ hari dimana nilai evaporatranspirasi maksimum terjadi pada bulan Maret dengan nilai sebesar 4,16 $\mathrm{mm} /$ hari sedangkan nilai evaporatranspirasi minimum terjadi pada bulan Juli sebesar 3,5 mm/hari. 


\section{Analisa Curah Hujan Efektif (Re)}

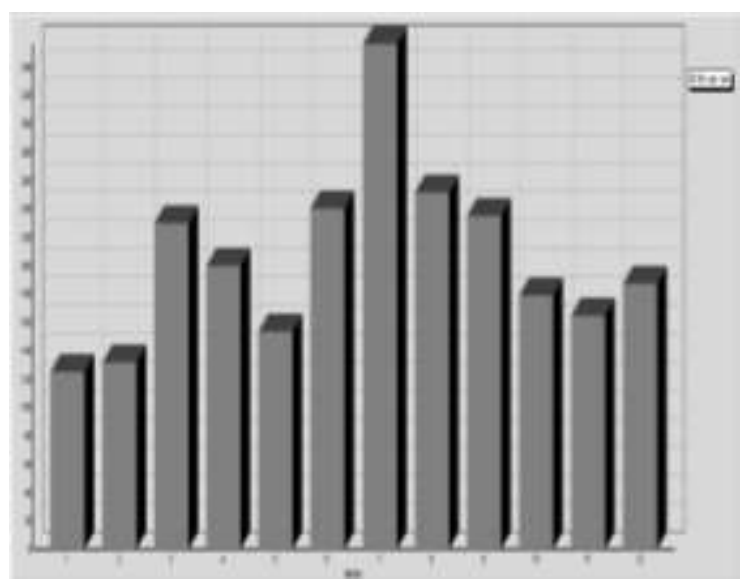

Gambar 3. Grafik Hasil Input Data Curah Hujan Pada Cropwat 8.0

Berdasarkan grafik diatas, maka curah hujan efektif maksimum terjadi pada bulan Juli, dimana jumlah pasokan air lebih besar jika dibandingkan dengan bulan Januari yang memiliki curah hujan efektif minimum. Total curah hujan periode pengamatan 10 tahun terakhir adalah $2453 \mathrm{~mm}$.

\section{Analisa Data Tanaman Jagung}

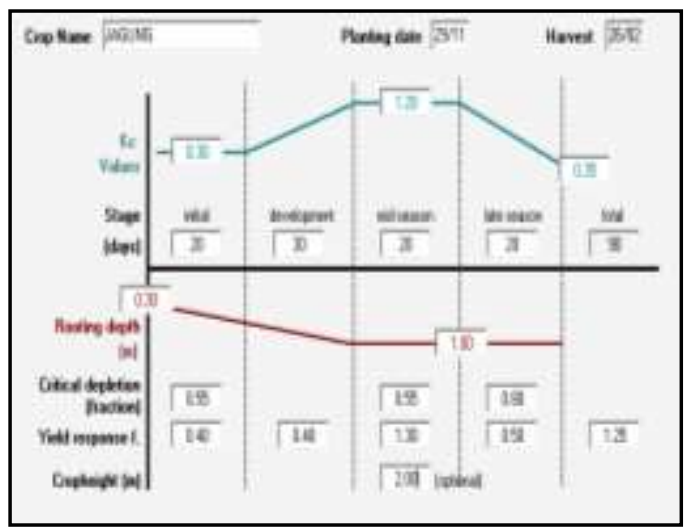

Gambar 4. Data Tanaman Jagung Tanggal Tanam 29 November (MT 1)
Berdasarkan analisa diatas, MT 1 ditanam pada tanggal 29 November dan akan di panen pada 26 Februari. Begitupun MT 2 s.d. MT 4. Jadi tanaman jagung mempunyai umur total 90 hari dengan rincian masa awal atau perkecambahan 20 hari, masa perkembangan 30 hari, massa pertengahan 20 hari, dan 20 hari pada masa akhir pertumbuhan. Untuk nilai koefisien tanamannya (Kc) yaitu sebesar 0,30 (masa awal), 1,20 untuk masa pertengahan dan 0,35 untuk masa lateseason (masa panen). Sedangkan kedalaman akar tanaman jagung adalah 1 meter.

\section{Analisa Data Tanah}

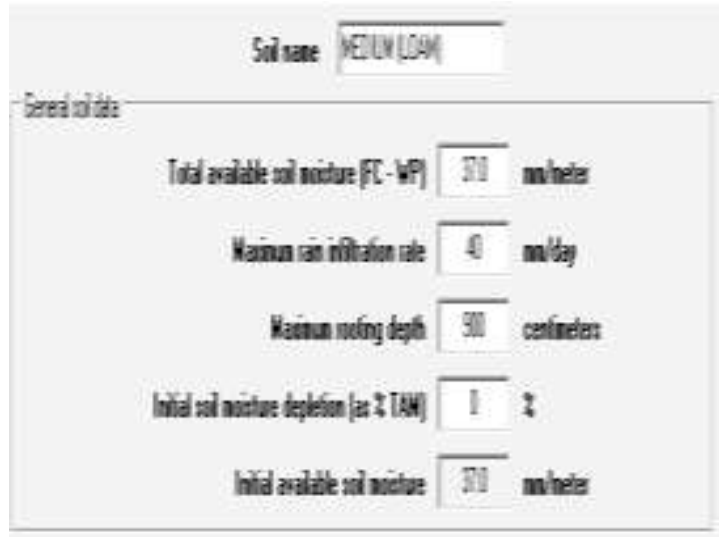

Gambar 5. Data Tanah dengan Tekstur Lempung

Gambar diatas menunjukkan nilai laju infiltrasi ini cukup tinggi yaitu sebesar $40 \mathrm{~mm} /$ hari sehingga air akan cepat masuk kedalam tanah bagian dalam. Sedangkan kedalaman maksimal perakaran tanaman jagung adalah $900 \mathrm{~cm}$. 


\section{Analisa Kebutuhan Air Tanaman (ETc)}

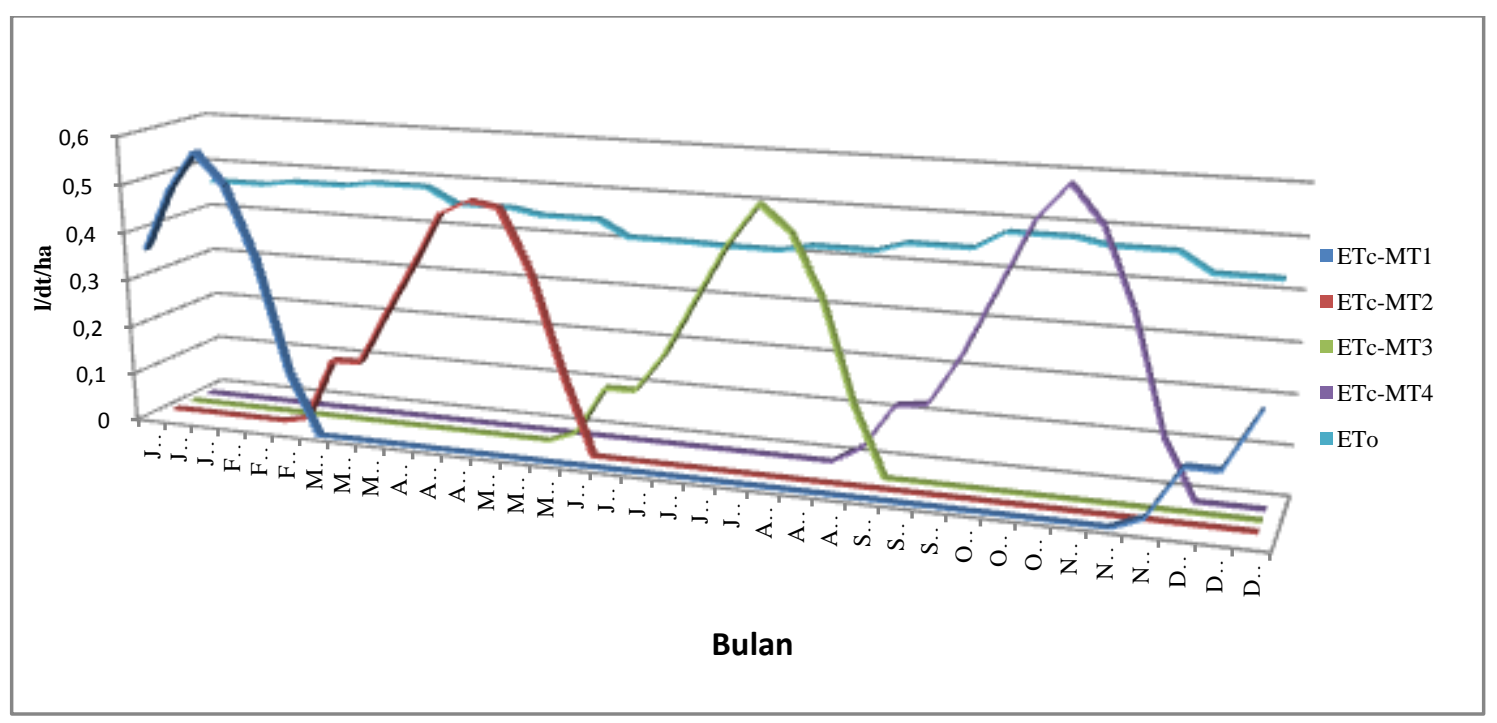

Gambar 6. Grafik Perbandingan Kebutuhan Air Tanaman Jagung dengan Evapotranspirasi Acuan

Dari hasil analisa diatas, maka kebutuhan air tanaman jagung maksimum rata rata dalam satu tahun sebesar $0.55 \mathrm{l} / \mathrm{dt} / \mathrm{ha}$ sedangkan nilai evapotranspirasi acuan rata rata dalam satu tahun adalah $0.44 \mathrm{l} / \mathrm{dt} / \mathrm{ha}$.

\section{Analisa Hasil Produksi Relatif Tanaman Jagung dengan Cropwat 8.0}

Untuk mengetahui hasil produksi tanaman jagung tiap masa tanam terlebih dahulu diketahui neraca lengas tanah dan prediksi penurunan produksinya akibat stress kekurangan air yang dinyatakan per musim dan setiap tahap pertumbuhan. Hasil produksi jagung berdasarkan hasil program Cropwat 8.0 didapat bahwa pada MT 1 sebesar $98,8 \%$, MT 2 sebesar 99,8\%, MT 1 sebesar 99,4\% dan pada MT 4 sebesar $98,5 \%$.

\section{PENUTUP}

\section{Kesimpulan}

1. Ada dua faktor yang ditinjau dalam analisa kebutuhan air tanaman yaitu sebagai berikut.

a. Pengaruh faktor Evapotranspirasi acuan, maka kebutuhan air tanaman (ETc) pada MT1 = 2,96 1/dt/ha, MT2 = 2,912 1/dt/ha, MT3 = 2,73 1/dt/ha dan MT4 = 3,02 1/dt/ha.

b. Pengaruh stress kekurangan air di daerah perakaran, maka kebutuhan air tanaman (ETa) pada $\mathrm{MT} 1=2,93 \mathrm{l} / \mathrm{dt} / \mathrm{ha}, \mathrm{MT} 2=$ 2,908 1/dt/ha, MT3 = 2.72 1/dt/ha dan MT4 = 2,98 1/dt/ha. 
2. Hasil produksi tanaman jagung maksimum terjadi MT2 sebesar $99,8 \%$ dimana penurunan produksinya sangat kecil $0,2 \%$. Hal ini menunjukkan defisit air untuk tanaman relatif kecil. Sedangkan hasil produksi tanaman jagung minimum terjadi pada MT4 sebesar 98,5\% dengan penurunan produksinya $1,5 \%$ dimana tingkat deplesi lengas tanah selama periode tanam sangat besar sehingga jumlah air yang dibutuhkan untuk mengisi daerah perakaran pun semakin besar.

\section{DAFTAR PUSTAKA}

Allen,R.G., L.S. Pereira, D. Raes and M. Smith. 1998. Irrigation and Drainage Paper 56. Guidelines for Predicting Crop Water Requirements. Rome, Italy : FAO

Al-Jamal M.S., T.W. Sammis, S. Ball and D. Smeal. 1999. Yield-Based, Irrigated onion crop coefficients, Applied Engineering in Agriculture, 15(6):659-668

Balitbang Deptan. 2006. Sifat Fisik Tanah dan Metode Analisisnya. Bogor: Agro Inovasi

Chay, Asdak. 1995. Hidrologi dan Pengeloaan daerah Aliran Sungai. Yogyakarta: Gadjah Mada Press

Doorenbos J. and A.M. Kassam. 1986. Yield Response to Water, Irrigation and Drainage Paper 33, Rome : FAO
Hakim, dkk. 1986. Dasar-dasar Ilmu Tanah. Lampung : Universitas Lampung.

IPB. , Topik 3. Prediksi Pengurangan Produksi Akibat Stress Kekurangan Air, [pdf], (http://web.ipb.ac.id/ tepfteta/.../pd f/Topik\%203\%20Kuliah-Produksidkk.pdf, diakses tanggal 13 November 2013 )

Phocaides, A. 2007. Handbook On Pressurized Irrigation Technique. Rome : Food And Agriculture Organization Of The United Station

Prijono, Sugeng. 2009. Aplikasi Cropwat for Windows Untuk Dasar Manajemen Sumber Daya Air di Petak Tersier. Jurnal Waktu. 7(1) : 88-92

Pristianto, H., Amri, I., \& Rusdi, A. (2014, May 9). Pedoman Penulisan Tugas Akhir Fakultas Teknik Universitas Muhammadiyah Sorong 2014. http://doi.org/10.17605/OSF.IO/4V TJM.

Sastrodarsono Suyono dan Kensaku Takeda. 2003. Hidrologi untuk Pengairan. Jakarta: PT Pradnya Paramita 
